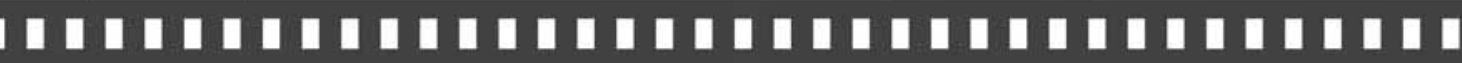 Pierre Verger e a construção da memória cultural afro-brasileira em 0 Cruzeiro: sentidos textuais através das fronteiras

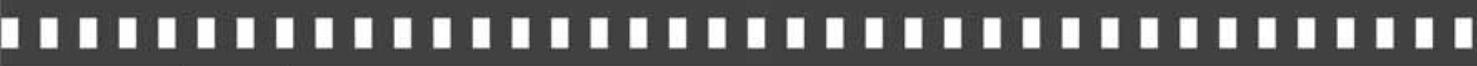

Julia Capovilla Luz Ramos

Beatriz Marocco 


\title{
Pierre Verger e a construção da memória cultural afro-brasileira em 0 Cruzeiro: sentidos textuais através das fronteiras*
}

Pierre Verger and the construction of african-brazilian's cultural memory in 0 Cruzeiro: textual meanings through borders

\author{
Julia Capovilla Luz Ramos** \\ Beatriz Marocco $* * *$
}

Resumo: A partir dos conceitos de fronteira, cultura e memória postulados por Yuri Lotman, o objetivo deste artigo é analisar as fotografias de Pierre Verger na matéria "Capoeira mata um!" da revista O Cruzeiro (1948), no intuito de entender a articulação de sentidos nos mecanismos de fronteiras semióticas para a construção de textos da cultura e da memória afrobrasileira, e contribuir para os estudos da Comunicação midiática.

Palavras-chave: Memória cultural; textos; fronteira; fotografia.

\begin{abstract}
Based on the concepts of border, culture and memory postulated by Yuri Lotman, this paper aims to analyze Pierre Verger photos in the article titled "Capoeira mata um!", published on $\mathrm{O}$ Cruzeiro magazine. The purpose is to understand the connection of meanings on semiotic boundaries mechanisms in relation to Afro Brazilian culture and memory text constructions in order to contribute to media communication studies.
\end{abstract}

Keywords: Cultural memory; texts; border; photography.

\footnotetext{
* Pesquisa financiada pela Capes para realização de Mestrado em Comunicação do Programa de Pós-Graduação da Unisinos, RS.

** Jornalista. Mestranda em Comunicação do Programa de Pós-Graduação da Unisinos, RS. Bolsista Capes. E-mail: jcapovilla8@hotmail.com.

*** Graduada em Jornalismo pela Universidade Federal do Rio Grande do Sul. Mestre em Comunicação pela Pontifícia Universidade Católica do Rio Grande do Sul. Doutora pela Universidade Autônoma de Barcelona. Atualmente é professora da Universidade do Vale do Rio dos Sinos. E-mail: bmarocco@unisinos.br.
} 


\section{As fronteiras possibilitam o significado}

As reflexões deste artigo partem dos conceitos de fronteira, cultura e memória postulados por Yuri Lotman ${ }^{1}$. A questão central é pensar de que maneira as fotorreportagens de Pierre Verger para a revista $O$ Cruzeiro $^{2}$, como textos articulados pelos mecanismos de fronteira, contribuíram para a construção da memória cultural afrobrasileira.

Primeiramente, verificamos que Yuri Lotman, bastante influenciado pelo modelo físico-matemático de comunicação, entendia a cultura como "memória não hereditária da coletividade" (LOZANO, 1999, p.III) e que as informações que a constituíam eram acumuladas, conservadas e transmitidas sem dificuldades. Porém, ao perceber que o ruído que tanto os matemáticos da comunicação procuravam eliminar, era não somente inerente ao processo comunicacional como fundamental para o seu desenvolvimento, Lotman passou a usar o termo tensão para caracterizar o campo de forças entre os espaços de emissão e de recepção dessas informações. São emissores e receptores que "lutam" para se comunicar.

Portanto, para que a comunicação seja possível e a entendendo como um subsistema semiótico do sistema linguístico, consideramos que o ponto de partida não deveria ser o signo isolado, mas a interação entre os signos e suas significações. Somente essa interação é capaz de gerar ruído, isto é, processar novas informações, novos sentidos. E mais: para que os sistemas semióticos possam existir é preciso que estejam, ainda, em um ambiente adequado; um espaço onde as semioses possam ocorrer. Assim como a vida não existe fora da biosfera, os sistemas semióticos não existem fora da semiosfera.

\footnotetext{
${ }^{1}$ Crítico formalista russo, semiótico e estruturalista. Integrante da Universidade de Tartu, na Estônia. Nasceu em 28/02/1922, em Petrogrado, Rússia, e faleceu em 28/10/1993, em Tartu. ${ }^{2}$ A revista $O$ Cruzeiro, fundada no ano de 1928 por Assis Chateaubriand, foi uma das mais importantes revistas semanais brasileiras, chegando à tiragem de 850 mil exemplares por semana na década de 50. (NETTO, 1998, p.123).
} 
Para Lotman (1999), a semiosfera é o local onde a cultura se constrói. É onde os acontecimentos ganham significação, onde a comunicação é possível; é o campo do conhecimento e da memória. Este ambiente possui fronteiras que filtram o que vêm do exterior e os "traduzem” para a linguagem interior. "Um procedimento que consiste na semiotização do que entra de fora e sua conversão em informação”. ${ }^{3}$ (LOZANO, 1999, p.IV). Uma fronteira em que a linha que separa o que está fora é a mesma que agrupa o que está dentro; capaz de gerar novos conteúdos ao formar espaços de intersecção, mas muito mais pela tensão exercida pelos conteúdos externos do que pelas trocas ocorridas internamente. É somente neste espaço semiótico específico que a cultura pode se constituir, já que a sua manifestação se realiza por meio de textos.

Textos, para o autor, significam a inter-relação dos sistemas de signos verbais e não verbais usados para comunicar. Conforme Sanches:

seu significado é constituído na correlação [...] com outros sistemas de significado mais amplos, com outros textos, com outros códigos, com outras normas presentes em toda cultura, em toda sociedade. Portanto, compreender um texto (artístico ou não) é compreender não só as relações intra-textuais, senão também as relações extra-textuais e as que surgem de confrontar estas com aquelas. ${ }^{4}$ (SANCHES apud TAGÉ, 2009).

Como estes textos podem se completar, assim como podem se opor, eles causam assimetrias e paradoxos na semiosfera, sendo possível se articularem somente pelos mecanismos de fronteira. Por isso, a fronteira é um conceito tão caro à obra de Lotman, já que é ela que possibilita os significados dos textos da cultura.

\footnotetext{
${ }^{3}$ Tradução livre do original: "Un procedimento que consiste en la semiotización de lo que entra de afuera y su conversión en información”.

${ }^{4}$ Tradução livre do original: "con otros sistemas de significado más amplios, con otros textos, con otros códigos, con otras normas presentes en toda cultura, en toda sociedad. Por lo tanto, compreender un texto (artístico o no) es compreender no solo las relaciones intratextuales, sino también las relaciones extratextuales y las que surgen de confrontar éstas con aquéllas.”
} 


\section{A mídia e a antecipação da cultura}

No mundo midiatizado em que vivemos, é inevitável aceitar que "a materialidade e o conteúdo da semiosfera é hoje, em grande medida, processada pelos aparatos midiáticos”. (HENN, 2007). Contudo, nossa hipótese vai além: o conteúdo da semiosfera é processado pelas mídias desde que elas passaram a ser as operadoras centrais da sociedade. Afinal, são as mídias que, na maioria dos casos, impressas ou eletrônicas, transformam os ruídos em textos da cultura por meio de "estratégias de apropriação", construindo uma normalidade. Neste sentido, a mídia hegemônica tem papel fundamental.

[...] a mídia hegemônica tende a tudo estruturalmente padronizar, gerando uma espécie de dissipação nos extratos da cultura considerados indigestos. Mas nas fronteiras culturais observam-se operações semióticas importantes. Estes extratos podem sair do silenciamento e recomporem-se com intensidade. [...] O mercado, ao necessitar de novidades, pode se apropriar e reduzir o caráter inventivo destas produções. (HENN, 2007).

É assim que as mídias passaram a ser os grandes agentes dos processos de construção da memória coletiva que, para Lotmam, era sinônimo de cultura. Por sua vez, a memória está sempre vinculada à lembrança de eventos passados. Ela só é possível com certo distanciamento histórico-temporal e, portanto, os textos da mídia são sempre uma antecipação, isto é, construtos periódicos de culturas. É a partir da articulação destes textos ou sistemas de signos que podemos recorrer à memória. Mas esta (re)construção é sempre tencionada; ao mesmo tempo em que se busca lembrar as experiências históricas passadas, geram-se novas memórias e apagam-se outras. Essa "luta" travada na memória revela que a cultura é sempre uma questão de reconhecimento e pertencimento fronteiriço; uma disputa do dentro-e-fora. 
Isso quer dizer que se reconhece a cultura em oposição aquilo que ela não é. [...] A cultura ao se constituir nesta intervenção sobre o fundo de não cultura, ganha materialidade como um sistema de signos no qual está pressuposta a configuração de linguagens e textos. (HENN, 2007).

A produção da cultura necessita, todavia, de permanente diversificação que garanta tanto a sua cristalização quanto a sua perenidade. É preciso que o sistema se renove sem perder seu caráter essencial. E essa produção “originária” se dá por meio do que Lotman chamou de explosões, que nada mais são que ruídos oriundos dos espaços de nãocultura, ou seja, eventos ainda não traduzidos na semiosfera. Portanto, é possível perceber que, para se tornar memória, as manifestações culturais precisem passar por três estágios: "o momento da explosão originária, o momento da sua construção nos mecanismos da consciência e o momento da sua rearticulação nos mecanismos da memória”. (HENN, 2007). É justamente no terceiro estágio que a mídia participa ativamente para a consolidação dos textos de cultura.

\section{O contexto cultural brasileiro e as contribuições de Pierre Verger}

Conforme vimos até agora, os textos presentes nos dispositivos midiáticos podem ser considerados como fios que tecem a cultura em um dado momento histórico e num espaço semiótico, tramando "a grande colcha" da memória coletiva.

A revista $O$ Cruzeiro, uma das maiores mídias impressas existentes neste país, abarcava inúmeras pistas dos valores considerados primordiais para a construção da cultura brasileira. Mas ao selecionar e legitimar o que era de interesse do público leitor e o que deveria ser compartilhado socialmente, os profissionais da revista transformavam os "ruídos” em textos da cultura, não apenas para serem consumidos, mas para serem 
absorvidos no imaginário social, servindo de referência para os comportamentos socialmente aceitos. Neste caso, a revista

torna-se um monumento do instante para a história do cotidiano, um objeto de linguagem que deve ser decifrado em todos os seus elementos constitutivos e não apenas centrado no conteúdo temático. [...]. Se tudo significa, então, [...] não é válido captar apenas uma parte como olhar uma estátua sem conhecer seu pedestal de base e sem interagir com a inscrição que lhe acrescenta sentidos, sem compreender a semiosfera que os legitima. (TAGÉ, 2009, p.2-3).

No início do século XX, no Brasil, a atividade fotográfica era ainda muito pontual. De modo geral, ou os profissionais ganhavam para fazer retratos ou as "elites" tinham a fotografia como um hobby. Dentre os fotógrafos profissionais, raríssimos eram os que trabalhavam para a imprensa.

Porém, ainda nas primeiras décadas, começava a nascer um novo jeito de fotografar muito por influência dos estrangeiros que passaram a atuar como fotojornalistas ${ }^{5}$ na imprensa brasileira. Este novo jeito deixava para trás o caráter exótico do povo brasileiro presente nas fotografias do século XIX e passava a apresentar uma visão mais ampla de cultura.

Nascida em 1928, a revista O Cruzeiro contratou o maior contingente de fotógrafos do país. A revista, na qual havia apenas dois repórteres fotográficos em 1943, chegou a comportar 20 fotógrafos em 1952. Inicialmente, as imagens eram distribuídas aleatoriamente nas páginas da revista, sem diagramação nem local definido. Mas isso mudou quando muitos fotógrafos europeus experientes vieram para o Brasil em função dos conflitos durante a Segunda Guerra Mundial e passaram a colaborar com a publicação.

\footnotetext{
${ }^{5}$ Fotojornalista é quem trabalha com fotojornalismo, também conhecido como repórter fotográfico. Por fotojornalismo entendemos fotografias que possuam a notícia como foco principal, o registro de imagens que sejam síntese da notícia, o momento visual simbólico, o clímax da ação, o registro de uma cena, a representação da "realidade". (RAMOS, 2006, p.129).
} 
Nos anos 40, com a colaboração desses profissionais, implantavase um novo modelo de fotorreportagem. Pela primeira vez no Brasil, as colunas teriam localização fixa no bojo da revista, e estabeleceram-se algumas editorias. As fotografias passaram a ser hierarquizadas e diagramadas nas páginas de forma que oferecessem a mais perfeita compreensão temporal dos acontecimentos narrados e conduzissem à leitura da matéria. Fotografias começam a funcionar também como manchetes; as reportagens abriam com belas e significativas imagens sangradas (ocupando toda a superfície de uma página), sobre as quais eram vazados os títulos e os créditos. (A FOTOGRAFIA..., 1993, p.24).

Os repórteres fotográficos começaram, então, a trabalhar em dupla com os jornalistas que assinavam as reportagens. As fotografias deixaram de ser apenas ilustrações enormes sobre os assuntos em pauta, passando a ser o principal produto da revista.

O Cruzeiro inovou não só por criar a maior equipe de fotógrafos até então existente no país [...], mas também por deixar que eles formassem dupla com os repórteres com quem tinham mais afinidade e se especializassem nos assuntos de seu interesse. [...] Os fotógrafos participavam ativamente das reuniões de pauta. Tinham todas as condições de trabalho disponíveis na época, podendo fretar aviões e viajar quando achassem necessário. Faziam reportagens que demandavam longas pesquisas chegando a publicá-las em capítulos (algumas duravam mais de um mês), coberturas internacionais e editavam as fotografias junto com os redatores. (COELHO, 2006, p.85).

Desde que esteve pela primeira vez, embora rapidamente, no Brasil, em 1940, o fotógrafo francês Pierre Verger sempre quis retornar e fixar residência no país. Mas somente com o contrato para trabalhar na revista O Cruzeiro, em 1946, é que conseguiu seu visto de permanência.

A atividade profissional em O Cruzeiro permitia a Verger finalmente ficar no Brasil como desejava desde a sua primeira estada em 1940 [...] Verger foi diretamente para o nordeste, atuando in loco [...] Escolheu Salvador como ponto de partida para inúmeras viagens 
que realizou durante os anos de 1946 a 1951, quando de sua primeira contratação para $O$ Cruzeiro. Estes anos foram fundamentais para que Verger descobrisse, nas suas sucessivas viagens pelo Nordeste, e até países vizinhos no Caribe, os aspectos de uma cultura popular que até antão, dentro de um discurso voltado para o desenvolvimento e a chegada do progresso no país, ou eram desconhecidos para o público das metrópoles ou então vistos como elementos de uma cultura popular exótica dentro da cultura nacional, normalmente designada como folclore. (LÜHNING, 2004, p.17-18, grifos do autor).

A publicação de suas reportagens fotográficas sobre o Brasil e principalmente sobre a cultura popular do nordeste, fez que o próprio brasileiro descobrisse o seu país.

Certamente, Verger ocupa um lugar de destaque como fotógrafo no universo da fotografia e de estudos de documentação e visibilização da cultura brasileira, pois realmente tornou visível o que para muitos ficava oculto pelo véu de um regionalismo pálido ou significava uma demonstração e um atestado de atraso cultural, preferencialmente a ser esquecido e ignorado em vez de ser visto, olhado e divulgado. Um dos maiores interesses de Verger concentrava-se em entender culturas étnicas e suas particularidades e contribuir para a sua existência continuada. (LÜHNING, 2004, p.15).

Quanto ao material fotográfico de Pierre Verger publicado em O Cruzeiro também é possível dizer, conforme Maria Beatriz Coelho (2006), Marlise Regina Meyrer (2007) e Cláudia Pôssa (2009), que fazia parte da "linha editorial" definida pela revista e, mais amplamente, fazia parte de um plano "civilizatório” do governo brasileiro. “[...] A linha editorial da revista segue a proposta de veicular grandes temas nacionais, construir uma imagem do Brasil [...]. Defende o desenvolvimento nacional e a necessidade de superação do atraso brasileiro. [...].” (MEYRER, 2007, p.35).

Outros fatos dão indícios da preocupação do governo em mostrar a cultura popular brasileira, isto é, tirá-la dos “guetos” e trazê-la aos centros 
urbanos para ser apreciada e vivenciada. Foi na década de 30 que surgiram os primeiros cursos de Ciências Sociais e na década de 40 foi criada a Comissão Nacional do Folclore(CNFL), instituição paraestatal do Instituto Brasileiro de Educação, Ciência e Cultura (IBECC), organizada no Ministério das Relações Exteriores, para ser a representante brasileira na Unesco. Todavia, o interesse pelos estudos folclóricos brasileiros já era bastante evidente desde a década de 20, período de grande efervescência cultural do país, com o resgate do nacionalismo e surgimento do movimento antropofágico, em particular pela Semana de Arte Moderna de 1922. (VILHENA, 1997).

É neste contexto histórico-social, portanto, que Pierre Verger se inseriu como repórter fotográfico de $O$ Cruzeiro e se firmou como tal no Brasil a partir de 1946.

\section{Discursos textuais através das fronteiras: análise das fotografias de Pierre Verger na reportagem "Capoeira mata um!"}

Entender o contexto cultural em que Pierre Verger produziu suas fotorreportagens para a revista $O$ Cruzeiro é fundamental para o entendimento de seu trabalho e para o significado de seus textos da cultura afrobrasileira nas páginas da publicação. Afinal, as fotorreportagens de Verger fazem parte de um contexto. Porém, este contexto é tanto externo quanto interno, uma vez que nas próprias páginas da revista suas fotografias interagem com outros sistemas de signos que também lhe afetam e lhes dão significados. Segundo Tagé (2009, p.1-2),

sistemas de signos verbais entrelaçam-se aos sistemas de signos visuais de modo indissociável. [...]. O que é dito com palavras dilui-se ao que é dito com cores, traços, imagens, espaços em branco [...]. Impossível restringir-se a apenas um tipo de sistemas 
sígnico, como, por exemplo, apenas ao sistema verbal ou ao visual de fotos, infográficos e outros.

Neste sentido, a relação entre todos esses signos não deve ser quebrada. Destacar somente as fotografias de Verger e ignorar o contexto nas páginas da revista, rasgando a trama que lhe dá significados, seria uma operação de leitura incompleta e limitadora de sentidos. Vamos destacar, no entanto, algumas dessas relações, já que seria inviável dar conta de tudo neste artigo.

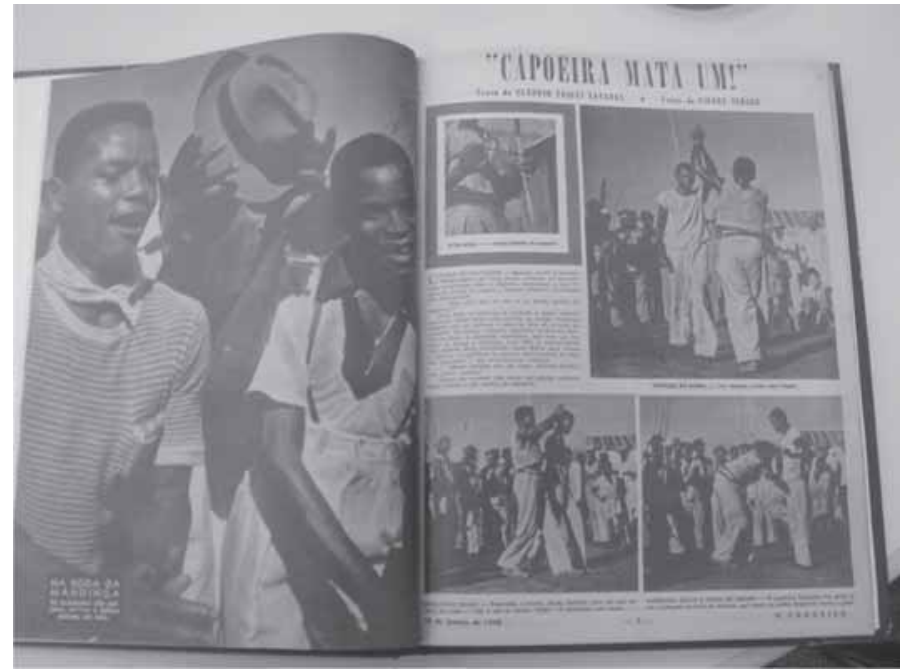

Figura 1 - “Capoeira mata um!” - primeiras páginas.

Fotografias de Pierre Verger e texto de Cláudio Tuiuti Tavares

Fotografia: Julia Capovilla Luz Ramos

Fonte: O Cruzeiro, 10 de janeiro de 1948, p.8-9

“Capoeira mata um!” é o título da reportagem com texto de Cláudio Tuiuti Tavares e fotografias de Pierre Verger, publicada no dia 10 de janeiro de 1948. Como no "samba de roda" ou "cantiga" que embala as rodas de capoeira $^{6}$, a manchete casa bem com as imagens feitas por Verger de dois homens executando alguns golpes da "luta" (três fotografias em plano

\footnotetext{
${ }^{6}$ A letra diz: "Zum zum zum, zum zum zum/ Capoeira mata um/ Zum zum zum, zum zum zum/ No terreiro fica um!”.(TAVARES, 1948, p.14).
} 
geral), junto a uma pequena imagem no canto esquerdo da página que revela no detalhe a "arma” que faz a capoeira disparar: o berimbau (Figura 1). A afirmação sobre o poder fatal da dança de raízes angolanas, executada pelos trabalhadores do cais em Salvador, é de autoria do mestre Juvenal Hermenegildo da Cruz, figura principal da matéria. É ele quem faz um inventário do legado da capoeira na cultura da Bahia:

[...] Quem for ao cais do Mercado Modelo, lá encontrará por certo os alunos de Juvenal que, nos descansos e nas horas de refeição, adquirem, na prática intensiva, as ancestrais virtudes e habilidades de Angola. Como seus alunos capoeiristas, Juvenal é um pacato e modesto estivador que adora as coisas e as histórias da Bahia de Todos os Santos. (TAVARES, 1948, p.10).

É possível perceber, em outro trecho da reportagem, que há a preocupação em contar as histórias dessa tradição e o jeito de ser dos capoeiristas:

Donde vem esta tão vistosa e popularíssima capoeira? Será uma dança negra, um dos ramos do vigoroso tronco das danças fetichistas, de que a Bahia é tão rica? Ou uma luta como tantas outras? [...] Nas horas de folga, a rampa do mercado pertence aos capoeiristas. Afigura-se-lhes palco imenso onde suas pernas se agitam na "vadiagem", a pulsar a capoeira, ao som monótono e doloroso do berimbau, - o tin-tin que é uma obsessão amável. (TAVARES, 1948, p.10).

E o autor da matéria continua:

O capoeirista atual não traz uma "argolinha de ouro na orelha, como insígnia de força e valentia, e o nunca esquecido chapéu à banda”, como antigamente. $\mathrm{O}$ equilíbrio absoluto ante um ataque adverso e a perícia, a prontidão para a defesa e a investida, são o que caracteriza o bom executante da capoeira. "Mostra a junta, que eu digo quem és”, exclama o capoeirista. Gosta de vestir camisa de urucubaca, frouxa, com calças largas, que facilitam os movimentos das pernas e do corpo. É comum o capoeirista ter seu santo, que, infalivelmente, é Oxossi ou Ogum. (TAVARES, 1948, p.10). 


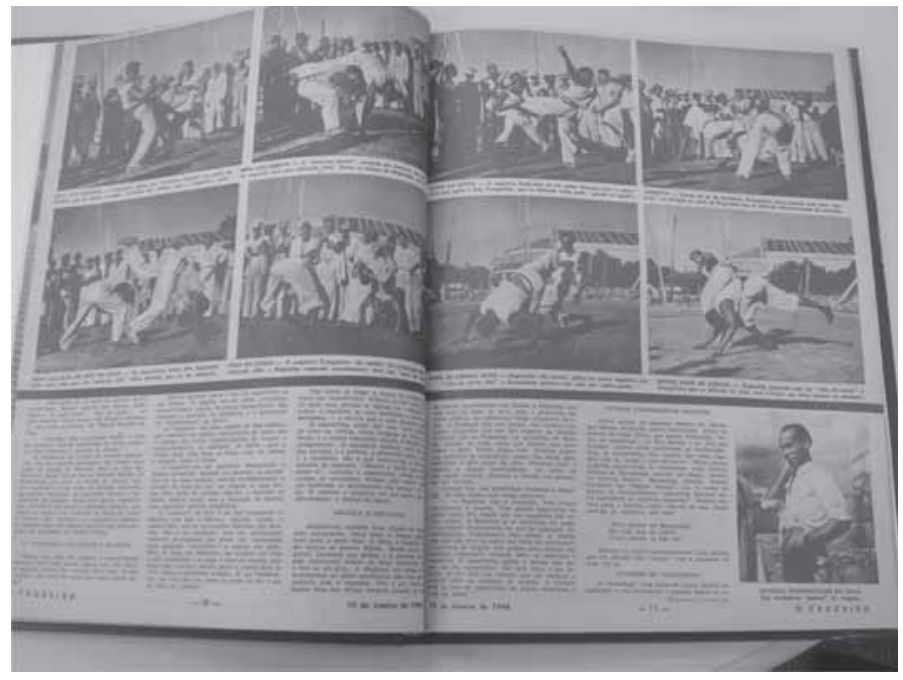

Figura 2 - “Capoeira mata um!” - páginas centrais. Fotografias de Pierre Verger e texto de Cláudio Tuiuti Tavares Fotografia: Julia Capovilla Luz Ramos

Fonte: O Cruzeiro, 10 de janeiro de 1948, p.10-11

É também o mestre Juvenal quem “explica” ao jornalista as regras do jogo e os golpes mais frequentes, amplamente explorados nas legendas e na fotorreportagem de Verger. Como uma espécie de passo a passo da luta ena tentativa de reconstruir os "movimentos" dos corpos dos lutadores, as fotografias foram publicadas em sequência, conferindo-lhes a marca da continuidade, da progressão temporal inerente à narrativa, e presentificando as ações dos personagens. Elas ficam dispostas nas margens superiores das páginas 9 (Figura 1), 10 e 11 (Figura 2), e 12 (Figura 3) de O Cruzeiro, o que já lhes garante destaque com relação ao texto escrito.

Além dessas fotografias, há ainda uma que cobre toda a página 13: um retrato de dois homens, um deles sentado, tocando berimbau contra um muro, a céu aberto (Figura 4). Ao lado do tocador em pé, pendurada, está uma camisa de cor clara. Ela pode ser signo tanto da necessidade de "voltar ao trabalho" do capoeirista, que a despe para não amassá-la ou sujá-la durante a luta; ou signo do calor oriundo do esforço físico ou do sol de meio dia em Salvador. 


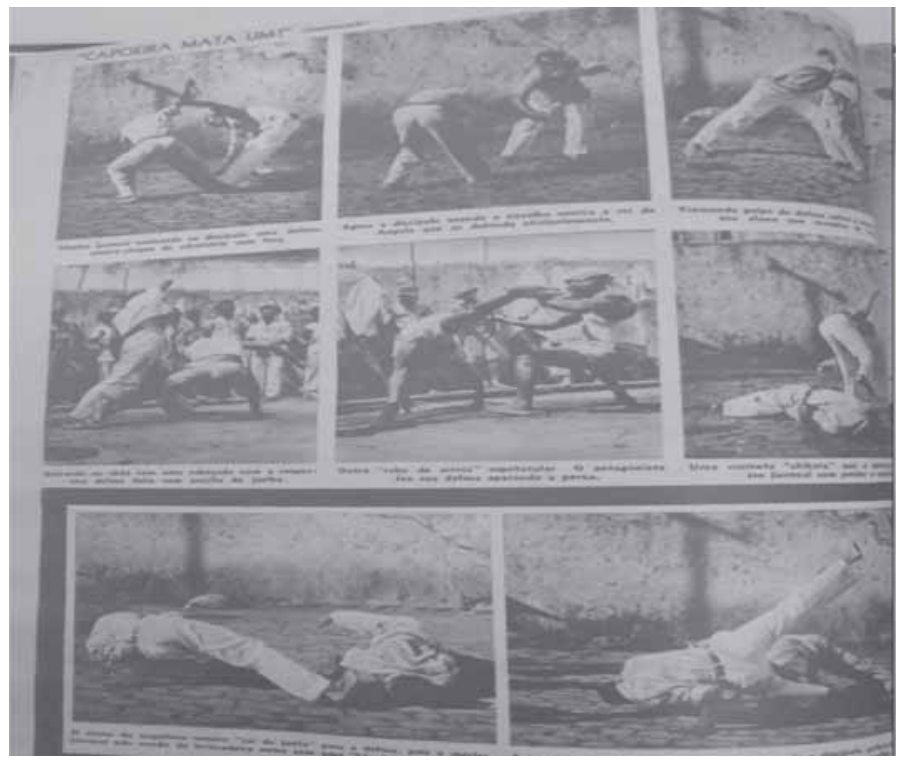

Figura 3 - "Capoeira mata um!” - páginas finais. Fotografias de Pierre Verger Fotografia: Julia Capovilla Luz Ramos

Fonte: O Cruzeiro, 10 de janeiro de 1948, p.12

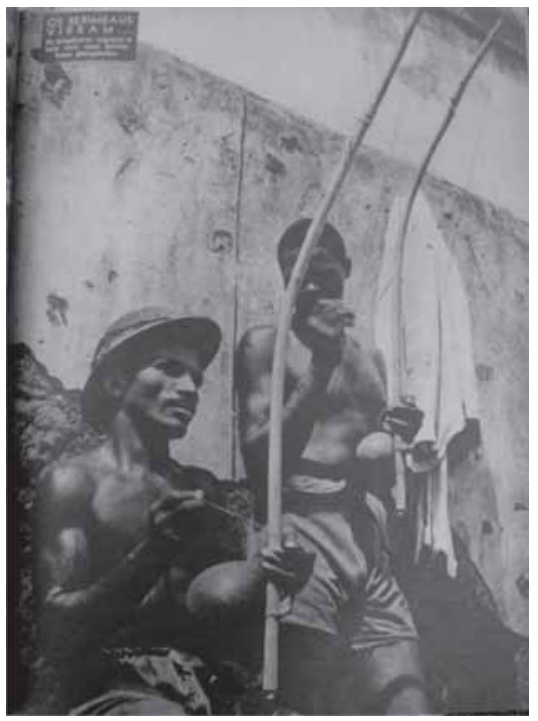

Figura 4 - "Capoeira mata um!" - retrato capoeiristas Fotografia: Pierre Verger

Fonte: O Cruzeiro, 10 de janeiro de 1948, p.13 
Notam-se, nas imagens, os signos que constituem uma "autêntica roda de capoeira": homens, na maioria negros, de bom porte físico e vestindo roupas soltas e brancas, dispostos ao redor dos lutadores em primeiro plano. Mais ao fundo, revela-se o telhado do Mercado Modelo de Salvador. Qual a mensagem construída? Num primeiro passar de olhos já é fácil responder: a capoeira é uma “dança”, "esporte” ou "luta”, cuja força, malemolência, ritmo e origem, são ideais para os corpos dos homens negros do cais.

Estas conexões entre os elementos sígnicos que compõem as fotografias precisam, além de ser concebidas pelo fotógrafo, ser percebidas pelos leitores para que seus sentidos sejam compreendidos. Por isso, é importante que uma imagem esteja em referência à outra; seja pelo caráter de complementação ou de contraste, sem necessitar necessariamente do contexto verbal. "Imagens podem funcionar como contextos de imagens”. (SANTAELLA; NÖTH, 2005, p.57).

Assim, as fotografias da matéria “Capoeira mata um!”, além de obedecerem a uma sequência cujos elementos internos se repetem, sofrem as influências estéticas e linguísticas de gêneros de fronteira como os quadrinhos, o cinema e a fotonovela.

O mecanismo da fronteira entre textos da mesma semiosfera permite que o espaço semiótico do jornalismo invada outros, como a forma do cinema, da ficção e da reportagem televisiva, dos procedimentos das histórias em quadrinhos e vice-versa. (TAGÉ, 2009).

Estes processos de atravessamento entre gêneros textuais permitem um diálogo entre formatos e os sentidos por eles gerados. Passam a construir cultura e memória graças aos processos de interação dos signos que os constituem e podem ser interpretados em espaços semióticos diversificados. Afinal, "somente no mecanismo da fronteira a significação da mensagem é comunicada plenamente”. (TAGÉ, 2009). É possível perceber nestas interações, que acontecem nos espaços extra e intramidiáticos, os registros culturais de um tempo-espaço que acabam por construir as marcas de uma sociedade. 
Cabe ressaltar que, como vimos anteriormente, no período em que Verger realizou essas fotografias - década de 40 e 50 - havia uma preocupação muito grande do governo brasileiro em construir, de certa forma, a cultura nacional na qual os brasileiros pudessem se reconhecer e, em diferentes graus, se identificar. Já que, conforme afirma Ortiz (1994), “a memória coletiva só pode existir enquanto vivência, isto é, enquanto prática que se manifesta no cotidiano das pessoas”. Portanto, a cultura popular precisava ser mostrada. Era preciso tirá-la dos “guetos” e trazêla aos centros urbanos para ser vivenciada, ainda que de forma contemplativa, por todos.

O olhar de Verger certamente foi fundamental para uma outra nova visão da cultura afro-brasileira e africana, porque abriu e criou uma nova forma de as pessoas olharem. Quando Verger começou a fotografar a grande maioria ainda não estava acostumada a enxergar o lado estético da cultura africana e afro-brasileira. (LÜHNING apud ANDRADE, 2005, p.105).

Claro que essas mudanças não foram imediatas e o reconhecimento do fotógrafo francês como agente deste processo só pode ser percebido a posteriori. Afinal, o tempo é elemento imprescindível para a análise da cultura e para a construção da memória, conforme nos apontou Lotman.

\section{Referências}

A FOTOGRAFIA na imprensa: material de apoio da exposição Êxodos de Sebastião Salgado. São Paulo: USP, 1993.

\section{ANDRADE, Rosane de. Fotografia e antropologia:}

olhares fora-dentro. 2.ed. São Paulo: EDUC, 2005.

COELHO, Maria Beatriz R. de V. O campo da fotografia profissional no Brasil. Varia História, Belo Horizonte, v.22, n.35, jan./jun 2006. p.79-99. 
HENN, Ronaldo. C. A memória da arte na semiosfera midiatizada. In: CONGRESSO INTERNACIONAL DE SEMIÓTICA, 3., 2007, Vitória. Anais... Vitória: ABES, 2007.

LOTMAN, Yuri M. Cultura y explosión: lo previsible en los processos de cambio social. Barcelona: Gedisa Editorial, 1999.

LOZANO, Jorge. Prólogo. In LOTMAN, Yuri M. Cultura y explosión:lo previsible en los processos de cambio social. Barcelona: Gedisa Editorial, 1999. p.I-VIII.

LÜHNING, Ângela (Org.). Pierre Verger: repórter fotográfico. Rio de Janeiro: Bertrand Brasil, 2004.

MEYRER, Marlise Regina. Representações do desenvolvimento nas fotorreportagens da revista $\boldsymbol{O}$ Cruzeiro (1955-1957). 2007. Tese (Doutorado em História) - Faculdade de Filodofia e Ciências Humanas, Pontifícia Universidade Católica do RS, Porto Alegre.

NETTO, Accioly. O Império de papel: os bastidores de O Cruzeiro. Porto Alegre: Sulina, 1998.

ORTIZ, Renato. Cultura brasileira e identidade nacional. São Paulo: Brasiliense. 3.ed. 1994.

PÔSSA, Cláudia. O repórter Pierre Verger. In: CONGRESSO BRASILEIRO DE CIÊNCIAS DA COMUNICAÇÃO, 32., 2009, Curitiba (PR). Anais... Curitiba: Intercom, 2009.

RAMOS, Júlia Capovilla Luz. Narrativa fotográfica: um diálogo entre princípios e métodos do jornalismo literário e projetos fotográficos temáticos. Conectiva: Revista de Estudos de Mídia e Linguagem, Pouso Alegre, v.4, n.6, jan./jun.2006. p.119-148. 
SANTAELLA, Lucia; NÖTH, Winfried. Imagem: cognição, semiótica, mídia. São Paulo: Iluminuras, 2005.

TAGÉ, Terezinha. Contaminações textuais e discursivas na imprensa contemporânea. Revista Rumores, São Paulo, v.1, n.6, set./dez. 2009. p.10.

TAVARES, Cláudio Tuiuti (texto); VERGER, Pierre (fotografias).

Capoeira mata um!. O Cruzeiro, Rio de Janeiro, 10 jan. 1948. p.8-13.

VILHENA, Luís Rodolfo. Projeto e missão: o movimento folclórico brasileiro (1947-1964). Rio de Janeiro: Funarte, 1997. 